\title{
Sistem Kontrol Hexapod robot MSR-H01 Menggunakan Mikrokontroler ATMega 128
}

\author{
Yunifa Miftachul Arif \\ Teknik Informatika, Fakultas Saintek, UIN Maulana Malik Ibrahim Malang
}

\begin{abstract}
Abstrak Penelitian ini membahas tentang bagaimana model sistem kontrol hexapod robot menggunakan mikrokontroler ATMega 128. Hexapod robot yang digunakan sebagai objek dalam penelitian ini adalah kit MSR-HO1. Kit hexapod robot ini dilengkapi dengan sistem pBrain yang mengontrol setiap pergerakan mekaniknya. Komunikasi data antara mikrokontroler AVR ATMega 128 dengan pBrain menggunakan komunikasi serial RS 232. Hexapod robot pada penelitian ini dilengkapi dengan sensor ultrasonik untuk mengetahui kondisi lingkungan dan obstacle di sekitar robot. Selain itu ultrasonik juga menjadi input ATMega 128 untuk menentukan perintah gerak yang dikirimkan ke pBrain. Untuk menentukan gerakan mekanik, mode yang digunakan simkontrol pada pBrain adalah mode offroad. Hasil ujicoba yang telah dilakukan menunjukkan bahwa mode offroad dapat digunakan robot untuk berjalan di track datar, berkarpet maupun track bergelombang dengan kecepatan maksimal $7 \mathrm{~s} / \mathrm{m}$ pada track datar.
\end{abstract}

Kata kunci: kontrol, hexapod robot, ultrasonik, mode offroad

\section{PENDAHULUAN}

Robot adalah segala peralatan otomatis yang dibuat untuk menggantikan fungsi yang selama ini dilakukan oleh manusia. Namun dalam perkembangan selanjutnya, robot diartikan sebagai manipulator multi fungsional yang dapat diprogram, yang dengan pemrograman itu ditujukan untuk melakukan sesuatu tugas tertentu [1]. Agar dapat bekerja secara otomatis tentunya robot membutuhkan sensor-sensor untuk mengetahui kondisi lingkungannya. Robot yang dapat berpindah tempat atau yang biasa disebut sebagai mobile robot, umumnya juga memiliki sensor-sensor yang digunakan untuk mendeteksi objekobjek disekitar robot, terutama objek di area jalur pergerakannya.

Semakin pesat perkembangan teknologi secara umum saat ini membuat semakin pesat pula perkembangan terhadap teknologi sensor. Mulai dari sensor jarak, logam, suhu, panas, cahaya, sampai dengan sensor citra bisa didapatkan dengan mudah dan murah. Untuk mengetahui jarak objek dan obstacle, mobile robot dapat menggunakan sensor jarak. Sensor jarak yang dimaksud bisa menggunakan jenis sensor ultrasonik ataupun sensor inframerah.

Pada penelitian ini sensor jarak yang digunakan adalah jenis sensor ultrasonik. Proses sensing yang dilakukan pada sensor ini menggunakan metode pantulan suara untuk menghitung jarak antara sensor dengan objek sasaran [2]. Sensor ultrasonik adalah sensor yang bekerja dengan memanfaatkan gelomnbang suara, sehingga interferensi dari terang dan gelap cahaya lingkungan menjadi lebih kecil. Hal tersebut berbeda dengan prinsip kerja sensor infra merah, yang memanfaatkan pantulan cahaya untuk mengetahui jarak, sehingga lebih rawan terhadap interferensi cahaya di lingkungannya.

Sistem mobile robot diharapkan dapat mendeteksi dan mengetahui kondisi lingkungannya lebih luas, bukan hanya di depan robot tetapi juga di samping maupun di belakang mekanik robot. Sehingga dengan mengetahui lebih luas kondisi lingkungannya, sistem robot nantinya dapat merencanakan pergerakan menuju path tujuan, mencari jalur terpendek serta dapat merencanakan pergerakan untuk menghindari obstacle. Dengan menggunakan lebih banyak sensor, maka 
kondisi lingkungan yang diharapkan robot dapat mengetahui kondisi lingkungan lebih luas dan detail sesuai dengan yang diharapkan.

\section{TINJAUAN PUSTAKA}

\section{Robot Berorientasi Fungsi}

Sistem robot yang dibahas dalam penelitian ini termasuk kedalam model robot berorientasi fungsi, yang mempunyai komponen utama, antara lain: mekanik robot, sensor, aktuator dan sistem kontroler.

Gambar 1 berikut ini mengilustrasikan tentang sebuah diagram sistem robot yang berorientasi fungsi [5].

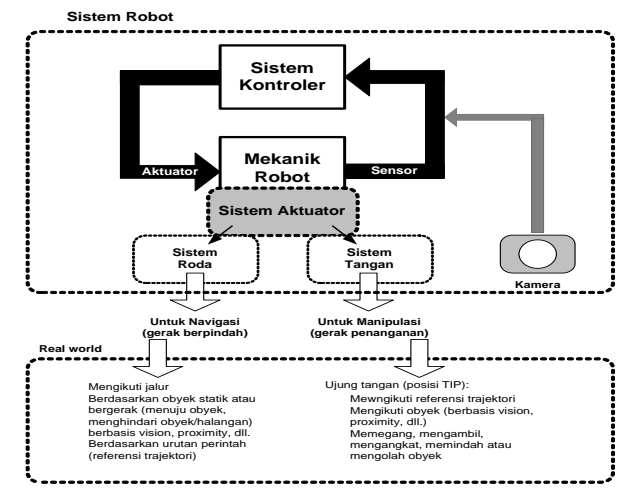

Gambar 1 Sistem Robot dan Orientasi Fungsi

\section{Hexapod robot MSR-H01}

Penelitian ini menggunakan Hexapod robot MSR-H01 sebagai sistem mekanik yang kemudian dikontrol dengan menggunakan mikrokontroler ATMega 128. MSR-H01 adalah modul robot yang memiliki 6 buah kaki dengan masingmasing 3 DOF (Degree Of Freedom) yang dimiliki setiap kakinya. Setiap DOF digerakkan oleh motor servo tipe $\mathrm{xx}$ sebagai aktuatornya. Model Hexapod robot MSR-H01 ditunjukkan melalui gambar 2 berikut ini.

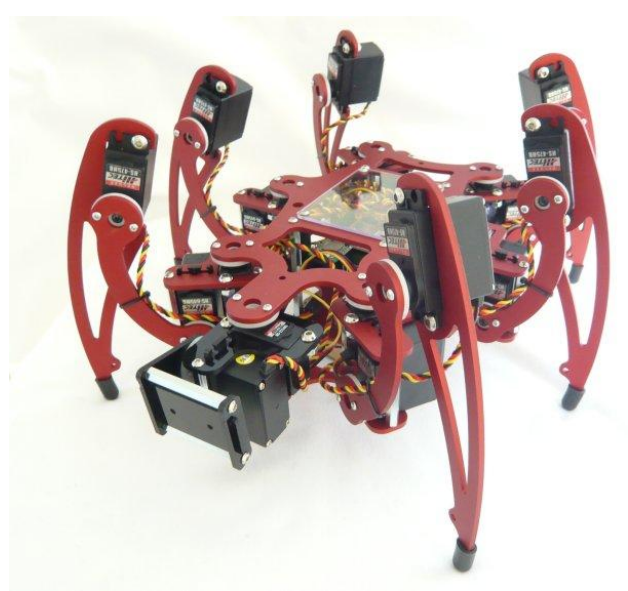

Gambar 2 Kit Hexapod robot MSR-HO1

Kit Robot MSR-H01 dilengkapi dengan sistem hardware yang mengontrol setiap servo pada sistem mekaniknya, sistem tersebut disebut dengan pBrain. Selanjutnya pBrain bisa di komunikasikan dengan sistem lain misalnya komputer atau jenis minimum mikrokontroler yang lain. Berikut ini adalah fitur yang dimiliki oleh pBrain Hexapod robot MSR-H01 [6]:

- Konfigurasi menggunakan terminal port atau control port menggunakan koneksi Bluetooth

- Kontrol gerak menggunakan terminal port atau control port

- Geometri badan yang dapat diatur

- Geometri kaki yang dapat diatur

- Konfigurasi re-map multiple servo output

- Konfigurasi Gait

- X,Y,Z rotasi dan translasi badan

- Berjalan ke segala arah

- Kalibrasi rotasi servo

- Servo reverse untuk tiap kaki

- Kalibrasi kaki

- 4 menu tipe gait

- 2 pilihan gaya berjalan

- 8 supported baud rates

- 3 PWM servo ranges, standart, extend, dan full $(500-2500 \mathrm{uS})$

- PWM terpisah untuk ketelitian $1 \mathrm{uS}$ resolusi PWM 


\section{Mikrokontroller Atmel AVR ATMega 128}

Sebagai pengendali fungsi input/output dalam penelitian ini digunakan jenis mikrokontroler AVR ATMega 128. AVR merupakan seri mikrokontroler CMOS 8bit buatan Atmel, berbasis arsitektur RISC (Reduced Instruction Set Computer). Hampir semua instruksi dieksekusi dalam satu siklus clock. AVR mempunyai 32 x 8 register general-purpose, timer/counter fleksibel dengan mode compare, interrupt internal dan eksternal, serial UART, programmable Watchdog Timer, dan mode power saving. Mempunyai ADC dan PWM internal. AVR juga mempunyai In-System Programmable Flash on-chip yang mengijinkan memori program untuk diprogram ulang dalam sistem menggunakan hubungan serial SPI. ATMega128 adalah mikrokontroler CMOS 8-bit daya-rendah berbasis arsitektur RISC yang ditingkatkan.

Kebanyakan instruksi dikerjakan pada satu siklus clock, ATMega128 mempunyai throughput mendekati 16 MIPS per $\mathrm{MHz}$ membuat disainer sistem untuk mengoptimasi komsumsi daya versus kecepatan proses [3].

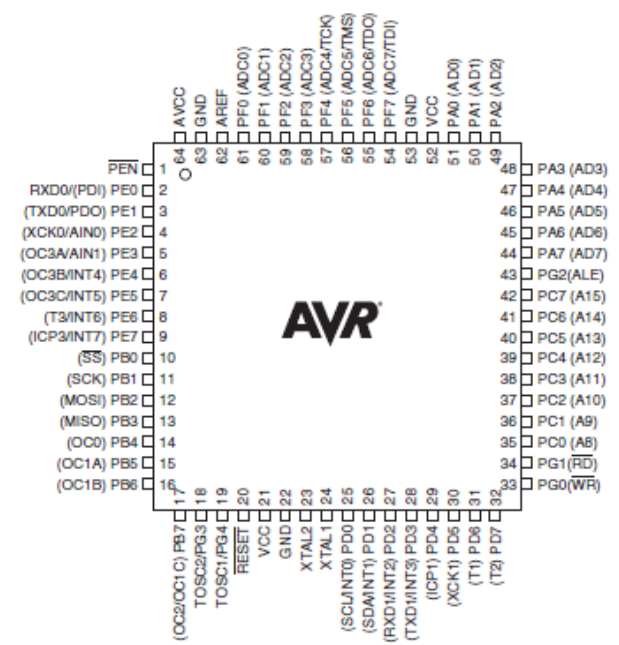

Gambar 3 Pin-pin ATMega 128

Pin-pin pada ATmega16 dengan kemasan 53-pin programmable I/O line sebagaimana ditunjukkan pada gambar 3 . Software yang digunakan untuk mengisi program pada mikrokontroller AVR adalah
CodeVision AVR dimana bahasa pemrograman yang digunakan adalah bahasa $\mathrm{C}$.

\section{Sensor Ultrasonik}

Sensor ultrasonik adalah sensor yang bekerja berdasarkan prinsip pantulan gelombang suara dan digunakan untuk mendeteksi keberadaan suatu objek tertentu frekuensi kerjanya pada daerah diatas gelombang suara dari $40 \mathrm{KHz}$ hingga $400 \mathrm{KHz}$. Besar amplitudo sinyal elektrik yang dihasilkan unit sensor penerima tergantung dari jauh dekatnya objek yang dideteksi.

Proses sensing yang dilakukan pada sensor ini menggunakan metode pantulan untuk menghitung jarak antara sensor dengan obyek sasaran. Jarak antara sensor tersebut dihitung dengan cara mengalikan setengah waktu yang digunakan oleh sinyal ultrasonik dalam perjalanannya dari rangkaian pengirim sinyal (Tx) sampai diterima oleh rangkaian penerima sinyal $(\mathrm{Rx})$ dengan kecepatan rambat dari sinyal ultrasonik tersebut pada media rambat yang digunakannnya, yaitu udara. Kecepatan rambat sinyal ultrasonik di udara adalah $342 \mathrm{~m} / \mathrm{s}$, sama dengan cepat rambat bunyi di udara [4].

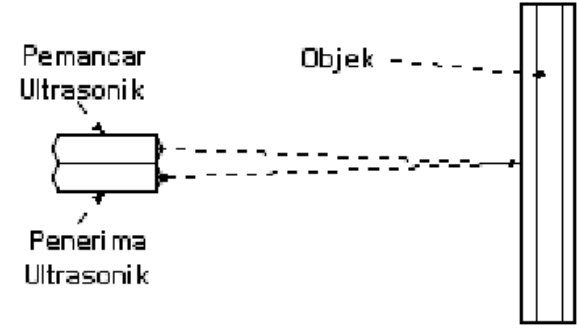

Gambar 4 Prinsip pemantulan gelombang Ultrasonik

Pada penelitian ini sensor ultrasonik digunakan sebagai indra robot untuk mengetahui jarak objek yang ada di sekitarnya.

\section{DESAIN DAN IMPLEMENTASI SISTEM}

Secara umum desain hexapod robot yang menjadi topik utama dalam penelitian ini dibagi menjadi beberapa bagian, mulai 
dari sensor, minimum mikrokontroler, dan aktuator. Selanjutnya dijelaskan melalui diagram blok yang ditunjukkan pada gambar 5.

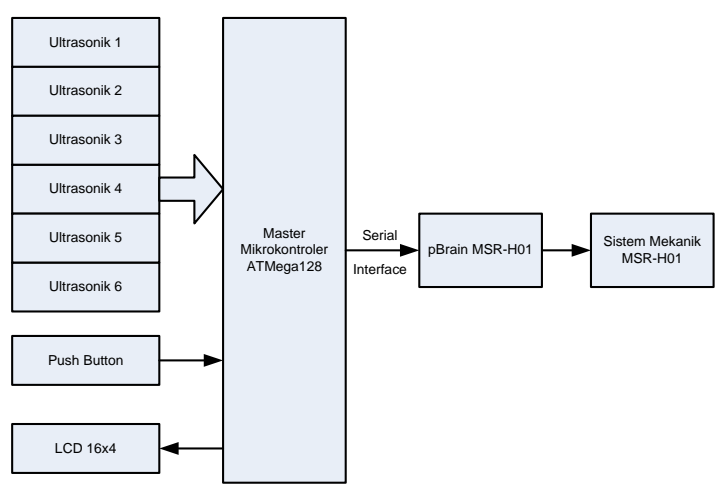

Gambar 5 Blok Diagram Sistem

Hexapod robot yang dibangun pada penelitian ini menggunakan 6 buah sensor ultrasonik yang berfungsi mendeteksi objek yang berada di lingkungan sekitar robot. Masing-masing sensor langsung dihubungkan ke mikrokontroler ATMega128, sebagai acuan mikrokontroler untuk memberi perintah gerak kepada kendali sistem mekanik yaitu pBrain MSR-H01.

Sistem seperti yang ditunjukkan pada gambar 5 dilengkapi dengan input pushbutton yang berfungsi sebagai user interface antara robot dengan manusia, khususnya untuk perintah start, reset, dan perintah lainnya. Selain itu ada juga LCD 16x4 yang digunakan sebagai output sistem yang dapat menampilkan beberapa informasi terutama berkaitan dengan kondisi masing-masing sensor. Hasil implementasi sistem hexapod robot sesuai dengan blok diagram yang dimaksud ditunjukkan pada gambar 6 .

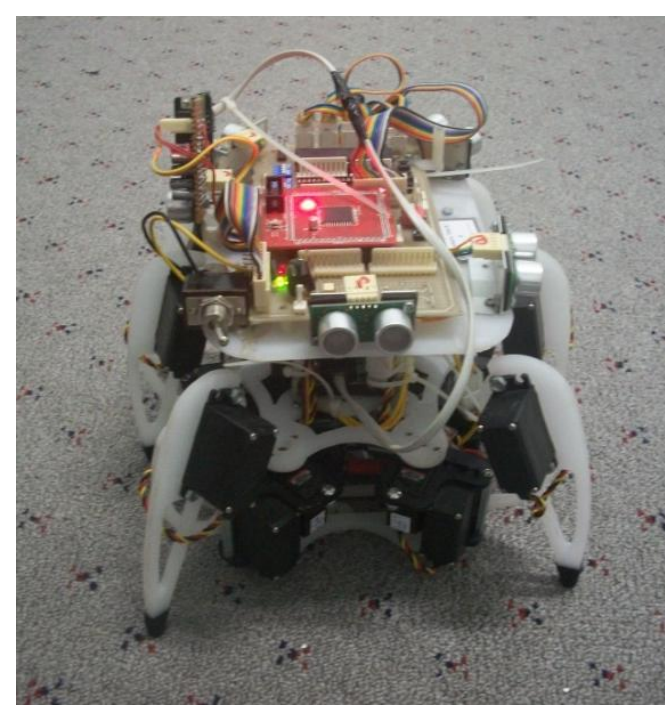

Gambar 6 Hexapod robot

\section{Sistem Kontrol Berbasis ATMega 128}

ATMega 128 pada penelitian ini digunakan sebagai control utama yang mengatur segala bentuk gerakan robot melalui pBrain, terhadap kondisi masukan sensor ultrasonik dan perintah dari push button. Konfigurasi PORT I/O ATMega 128 ditunjukkan melalui tabel 1.

Tabel 1 Konfigurasi PORT I/O ATMega 128

\begin{tabular}{|l|l|}
\hline PORT & Fungsi \\
\hline A.0, A.1 & Triger dan Echo Ultra 1 \\
\hline A.2, A.3 & Triger dan Echo Ultra 1 \\
\hline A.4, A.5 & Triger dan Echo Ultra 1 \\
\hline A.6, A.7 & Triger dan Echo Ultra 1 \\
\hline B.0, B.1 & Triger dan Echo Ultra 1 \\
\hline B.2, B.2 & Triger dan Echo Ultra 1 \\
\hline C.0 - C.7 & LCD Display \\
\hline D.2, D.3 & RX, TX komunikasi serial \\
\hline F.0 - F.3 & Push button \\
\hline
\end{tabular}

Rangkaian elektronik yang didalamnya termasuk minimum sistem ATMega 128 yang menjadi main control hexapod robot pada penelitian ini ditunjukkan pada gambar 7 . 


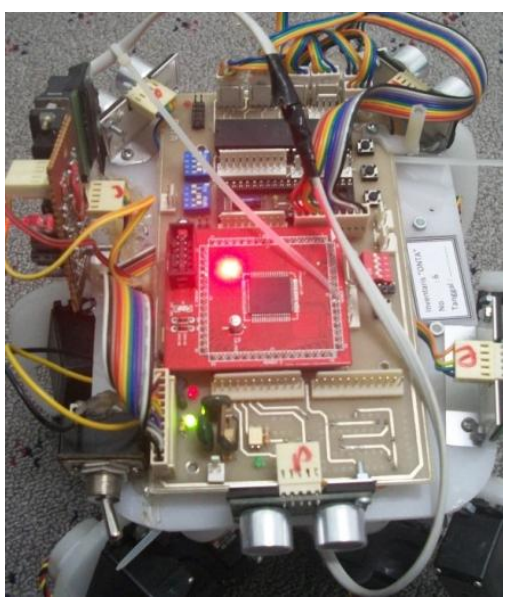

Gambar 7 Rangkaian Elektronik Hexapod robot

\section{Sistem Komunikasi Serial}

Sistem komunikasi data antara ATMega 128 dengan pBrain kit MSR-H01 adalah dengan menggunakan komunikasi serial. Setiap perintah dari ATMega 128 kepada pBrain dikirimkan melalui komunikasi serial dengan standart RS232. Implementasi antar muka yang dimaksud ditunjukkan melalui gambar 8 .

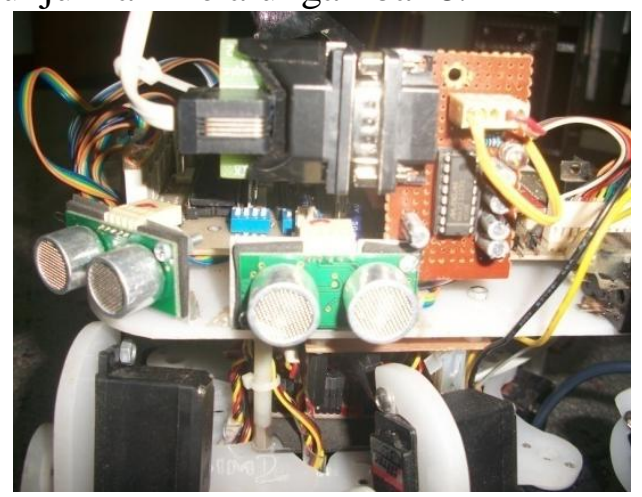

Gambar 8 Implementasi sistem komunikasi serial dengan RS232

\section{Konfigurasi Sensor Ultrasonik}

Sensor ultrasonik pada penelitian ini disusun dengan konsep melingkar seperti ditunjukkan pada gambar 9. Tujuannya adalah agar robot dapat mengetahui semua kondisi objek yang ada di lingkungan sekitarnya.

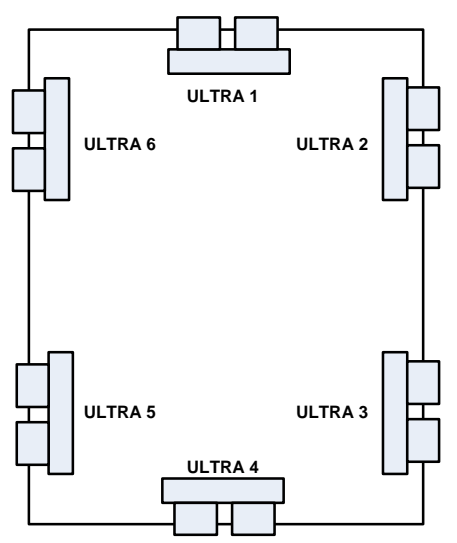

Gambar 9 Susunan sensor ultrasonik

\section{HASIL DAN PEMBAHASAN}

Hexapod robot yang menjadi bahasan dalam penelitian ini dapat secara otomatis bergerak berdasarkan input dari sensor ultrasonik yang dikontrol dengan menggunakan ATMega 128. Selanjutnya output dari ATMega 128 dihubungkan dengan kit pBrain agar dapat diterjemahkan ke dalam gerakan mekanik robot. pBrain memiliki karakteristik menunggu karakter “@@@" dari mikrokontroler sebelum dapat melaksanakan perintah-perintahnya melalui simkontrol. Perintah yang dikirimkan mikrokontroler kepada pBrain tersebut ditunjukkan pada tabel 2 . Sedangkan contoh perintah awal untuk dapat berkomunikasi dengan pBrain ditunjukkan dalam gambar 10 yang berisi sourcecode program dalam bahasa $\mathrm{C}$ yang dibuat dengan menggunakan CodeVision AVR. 


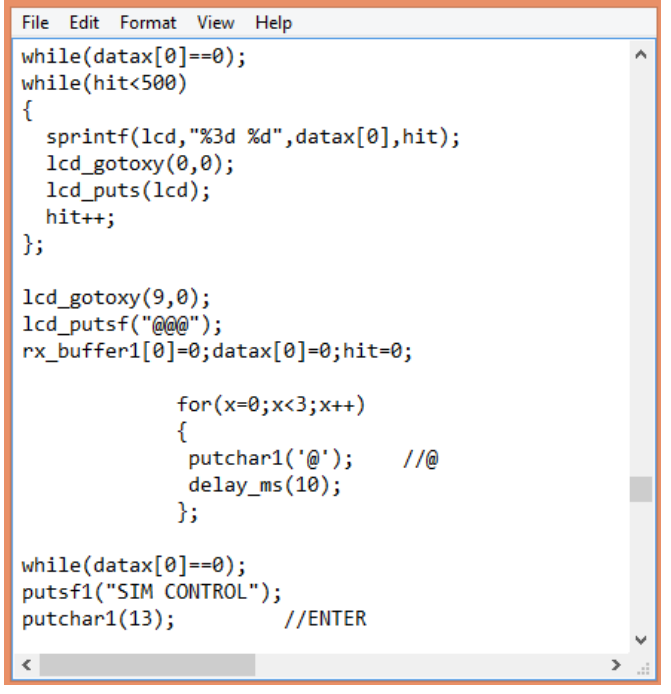

Gambar 10 Sourcecode komunikasi awal mikrokontroler dengan pBrain

Tabel 2 Perintah Mikrokontroler kepada pBrain

\begin{tabular}{|l|l|}
\hline Key & Deskripsi \\
\hline+ & Menaikkan Power Hexapod \\
\hline- & Menurunkan Power Hexapod \\
\hline SPACE & Stop hexapod \\
\hline$!$ & $\begin{array}{l}\text { Stop darurat (mematikan servo secara } \\
\text { langsung ) }\end{array}$ \\
\hline $\mathrm{W}$ & Maju \\
\hline $\mathrm{S}$ & Mundur \\
\hline $\mathrm{A}$ & Belok kiri \\
\hline $\mathrm{D}$ & Belok kanan \\
\hline $\mathrm{Q}$ & Crab kiri (jalan miring) \\
\hline $\mathrm{E}$ & Crab kanan (jalan miring) \\
\hline 1 & Wave mode 1 (pelan) \\
\hline 2 & Wave mode 2 \\
\hline 3 & Wave mode 3 \\
\hline 4 & Tripod mode (jalan cepat) \\
\hline 5 & Onroad mode (medan datar , cepat) \\
\hline 6 & $\begin{array}{l}\text { Offroad } \text { mode (pelan , medan } \\
\text { rintangan) }\end{array}$ \\
\hline 7 & $\begin{array}{l}\text { Menurunkan kecepatan transfer kaki } \\
\text { 0.1detik }\end{array}$ \\
\hline 8 & $\begin{array}{l}\text { Meningkatkan kecepatan transfer kaki } \\
\text { 0.1detik }\end{array}$ \\
\hline 9 & $\begin{array}{l}\text { Mereset kecepatan transfer kaki ke } \\
\text { default }\end{array}$ \\
\hline $\mathrm{B}$ & Reset posisi kaki ke normal \\
Mengaktifkan mode full 3D balance \\
\hline
\end{tabular}

Sedangkan contoh perintah untuk menghasilkan gerakan mekanik robot yang dikirimkan kepada pBrain ditunjukkan melalui gambar 11 .

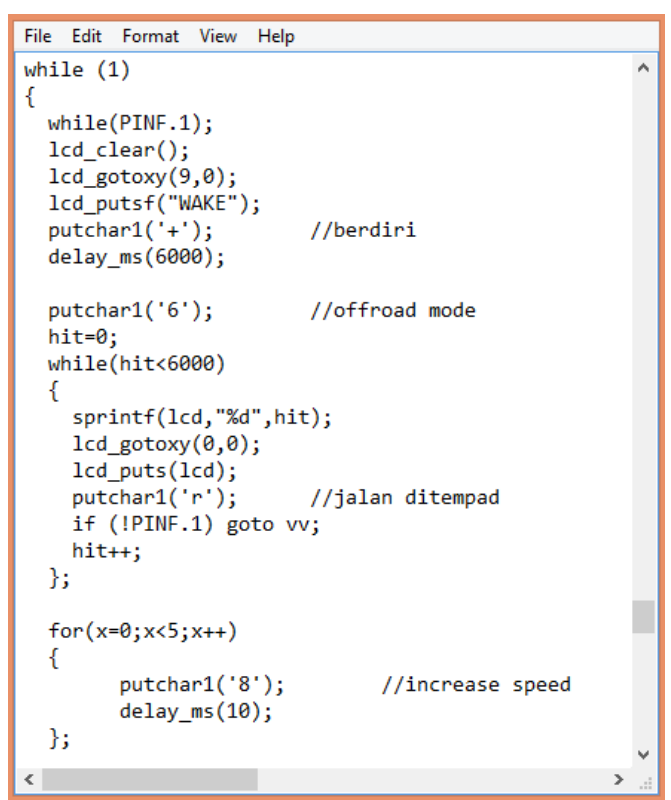

Gambar 11 Sourcecode perintah gerak mikrokontroler kepada pBrain

Gambar 11 menunjukkan beberapa perintah dasar yang dikirimkan kepada pBrain. Diantaranya adalah perintah berdiri dengan mengirimkan karakter "+", masuk ke dalam mode offroad dengan karakter "6", jalan ditempat dengan karakter " $r$ ", dan menambah kecepatan dengan mengirimkan karakter "8". Offroad mode yang dimaksud adalah gerakan robot dengan kaki berjinjit, sehingga badan robot dapat terangkat lebih tinggi, dengan tujuan agar dapat melewati medan yang tidak teratur / bergelombang.

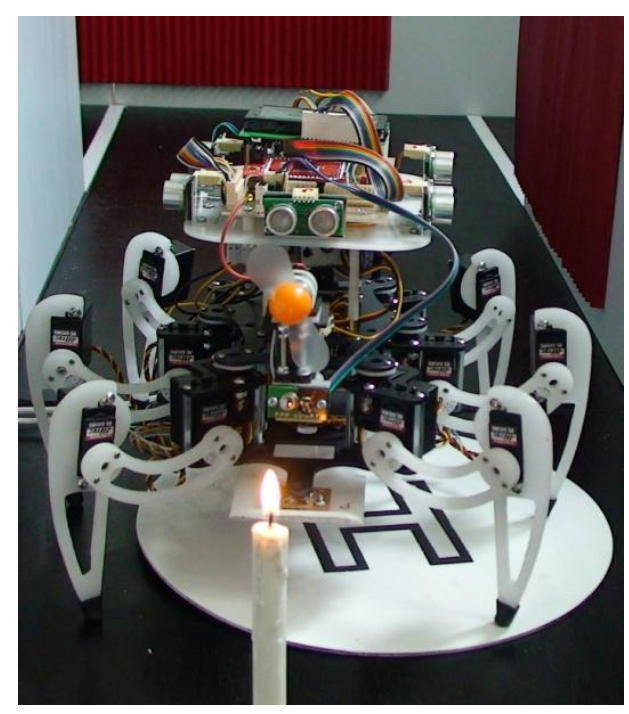

Gambar 12 Uji coba robot pada track 
Dalam tahap ujicoba, hexapod robot dijalankan pada beberapa model track, datar, datar di karpet dan bergelombang. Gambar 12 menunjukkan ujicoba robot ketika dijalankan pada track datar. Track bergelombang yang dimaksud dalam penelitian ini adalah track datar dengan beberapa obstacle penghalang, sehingga membentuk track yang bergelombang. Mode yang diujicobakan pada penelitian ini menggunakan mode offroad dan hasilnya ditunjukkan pada tabel 3 .

Tabel 3 Ujicoba hexapod robot dalam 3

\begin{tabular}{|l|l|l|}
\multicolumn{3}{|c}{ track } \\
\hline Ujicoba & \multicolumn{1}{|c|}{ Track } & $\begin{array}{c}\text { Kecepatan rata- } \\
\text { rata }\end{array}$ \\
\hline 1. & Datar & $7 \mathrm{~s} / \mathrm{m}$ \\
\hline 2. & Karpet & $13 \mathrm{~s} / \mathrm{m}$ \\
\hline 3. & Bergelombang & $16 \mathrm{~s} / \mathrm{m}$ \\
\hline
\end{tabular}

Sesuai dengan hasil ujicoba yang ditunjukkan pada tabel 3, bahwa pada dasarnya dengan menggunakan mode offroad hexapod robot masih dapat berjalan pada 3 track yang berbeda. Ditinjau dari segi kecepatannya, hexapod robot dapat berjalan lebih cepat pada track datar mencapai $7 \mathrm{~s} / \mathrm{m}$.

\section{KESIMPULAN}

Kesimpulan dan rencana penelitian lanjutan yang dapat dideskripsikan dari hasil penelitian ini adalah sebagai berikut:

1. Sistem control dengan menggunakan mode offroad terbukti dapat digunakan oleh hexapod robot MSR-H01 untuk dapat bergerak pada track datar, karpet, maupun bergelombang. Dengan maksimal kecepatan $7 \mathrm{~s} / \mathrm{m}$ pada track datar, dan paling lambat pada track bergelombang dengan kecepatan $16 \mathrm{~s} / \mathrm{m}$.

2. Perlu penelitian lebih lanjut tentang penggunaan mode control hexapod yang lain, diantaranya mode onroad dan mode tripod. Sehingga arah penelitian selanjutnya dapat membahas tentang sistem otomatisasi perubahan mode berdasarkan kondisi lingkungan yang ditemui.

\section{DAFTAR PUSTAKA}

[1] Yunifa Miftachul Arif. September 2011 Hardware Control Pada Robot Pemindah Bunga. Jurnal MATICS, No. 4, Vol. 4.

[2] Hani dan Slamet. Desember 2010. Sensor Ultrasonik SRF05 Sebagai Memantau Kecepatan Kendaraan Bermotor. Jurnal Teknologi, Volume 3 Nomor 2.

[3] .......,"datasheet ATmega128", www.atmel.com

[4] Suprapto, Sumardi, Iwan Setiawan. Rancang Bangun Robot Mobil Pemadam Api Berbasis Mikrokontroler AT89S52. Jurusan Teknik Elektro Fakultas Teknik Universitas Diponegoro.

[5] Pitowarno, Endra. 2006. Robotika : Disain, Kontrol, dan Kecerdasan Buatan. Yogyakarta: PT Andi Offset.

[6] Micromagic System. 2009. Configuration Guide : p.BrainHexEngine V1.2. www.micromagicsystem.com 